\section{Retrieval of a migrated stent during endoscopic ultrasound-guided drainage of duodenal diver- ticular abscess}

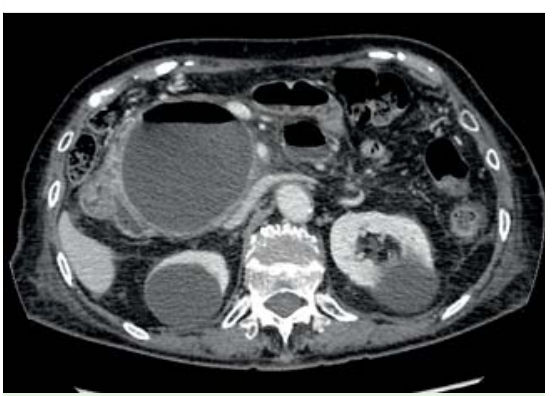

Fig. 1 Computed tomography showed a duodenal diverticular abscess, with air-fluid level.

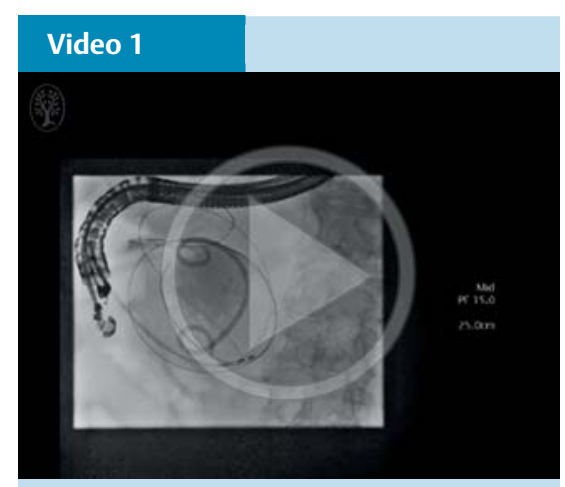

Retrieval of a migrated stent using endoscopic ultrasound scope with a basket catheter under fluoroscopy.

Endoscopic ultrasound (EUS)-guided drainage for an abdominal abscess has become recognized as a minimally invasive alternative to surgery. With regard to EUS-guided drainage of a pancreatic pseudocyst, the occurrence of stent migration into the pseudocyst is a relatively rare complication [1] and can be prevented by using double-pigtail stents [2]. This report describes endoscopic retrieval of a migrated double-pigtail stent during EUS-guided drainage of duodenal diverticular abscess.

A 91-year-old woman with upper right abdominal pain and fever was referred to our hospital. Computed tomography showed a duodenal diverticular abscess ( $\bullet$ Fig. 1). Therefore, EUS-guided drainage of the abscess was performed.

The abscess was punctured with a 19 -gauge needle, and a 0.025 -inch guidewire was placed. Subsequently, an additional guidewire was placed using a tri- ple-lumen catheter (Haber RAMP catheter; Cook Japan, Tokyo, Japan) ( $\bullet$ Fig. 2a). A 7-Fr double-pigtail stent was placed over the wire. However, before the nasobiliary drainage tube could be placed, the stent accidentally jumped into the abscess (॰ Fig.2b).

We opted to retrieve the migrated stent using a basket catheter. First, the triplelumen catheter was inserted over the remaining guidewire to place an additional guidewire. Then, a basket catheter (FG-V435P; Olympus Medical Systems Corp., Tokyo, Japan) was introduced into the abscess over the guidewire, and the migrated stent was removed by grasping its tip with the basket catheter ( $\nabla$ Fig. 2 c, - Video 1). Finally, a 7-Fr double-pigtail stent and a 7-Fr nasobiliary drainage tube were placed successfully ( $\bullet$ Fig. 2 d). The endoscopic retrieval of a migrated stent is technically challenging. In a few cases of pancreatic pseudocyst, migrated stents have been removed by forceps using a forward-viewing endoscope [35]. In our patient, the migrated stent was successfully retrieved by EUS scope using a basket catheter under fluoroscopy. Furthermore, it is important to place an additional guidewire during the procedure in case a guidewire slips out.

Endoscopy_UCTN_Code_CPL_1AL_2AD

Competing interests: None

\section{Sho Kitagawa, Keiya Okamura, Daiki Oku, Ai Minoura}

Department of Gastroenterology, Sapporo Kosei General Hospital, Sapporo, Japan

\section{References}

1 Varadarajulu S, Christein JD, Wilcox CM. Frequency of complications during EUS-guided drainage of pancreatic fluid collections in 148 consecutive patients. J Gastroenterol Hepatol 2011; 26: 1504-1508

2 Cahen D, Rauws E, Fockens $P$ et al. Endoscopic drainage of pancreatic pseudocysts: long-term outcome and procedural factors associated with safe and successful treatment. Endoscopy 2005; 37: 977-983

3 Kahaleh M, Shami VM, Conaway MR et al. Endoscopic ultrasound drainage of pancreatic
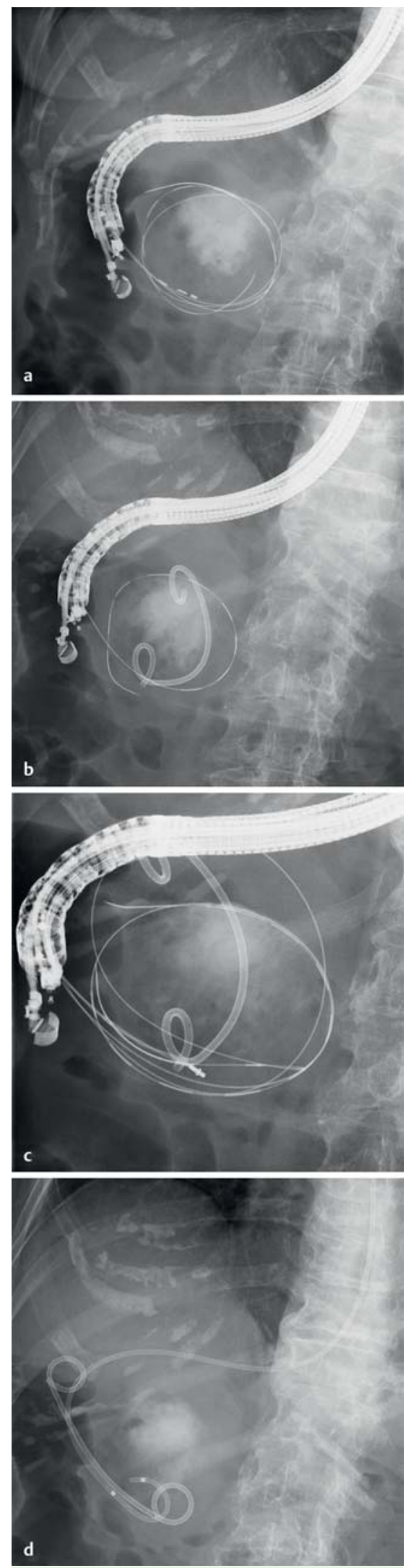

Fig. 2 Radiographic images. a Two guidewires were placed within the abscess using a triple-lumen catheter. b A 7-Fr double-pigtail stent accidentally jumped into the abscess. $\mathrm{c}$ A basket catheter grasped the tip of the migrated stent. d A 7-Fr double-pigtail stent and a 7-Fr nasobiliary drainage tube were placed successfully. 
pseudocyst: a prospective comparison with conventional endoscopic drainage. Endoscopy 2006; 38: 355 - 359

4 Varadarajulu S. EUS-guided retrieval of a migrated transgastric pancreatic stent. Endoscopy 2007; 39: E18-19

5 Lin L-F, Tung J-N. Difficult endoscopic retrieval of a migrated stent inside a pseudocyst Case Rep Gastroenterol 2008; 2: 199-202
Bibliography

Dol http://dx.doi.org/

10.1055/s-0042-116429

Endoscopy 2016; 48: E296-E297

(c) Georg Thieme Verlag KG

Stuttgart · New York

ISSN 0013-726X
Corresponding author

Sho Kitagawa, MD

Department of Gastroenterology Sapporo Kosei General Hospital

Kita 3 Higashi 8

Chuo-ku, Sapporo 060-0033

Japan

Fax: $+81-11-2715320$

bossa0405@yahoo.co.jp 